\title{
Structural Ableism: Defining Standards of Care Amid Crisis and Inequity
}

\author{
Gregory D. Snyder, MD, MBA
}

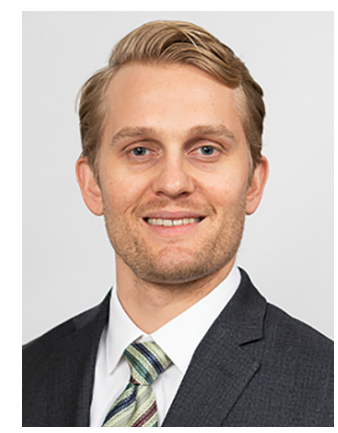

\section{Equitable Standards for All Patients in a Crisis}

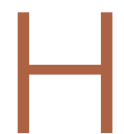

ealth care delivered during a pandemic instantiates medicine's perspectives on the value of human life in clinical scenarios where resource allocation is limited. The COVID-19 pandemic has fostered dialogue and debate around the ethical principles that underly such resource allocation, which generally balance (1) utilitarian optimization of resources, (2) equality or equity in health access, (3) the instrumental value of individuals as agents in society, and (4) prioritizing the "worst off" in their natural history of disease., State legislatures and health systems have responded to the challeges posed by COVID-19 by considering both the scarcity of intensive care resources, such as mechanical ventilation and hemodialysis, and the clinical criteria to be used for determining which patients should receive said resources. These crisis guidelines have yielded several concerning themes vis-à-vis equitable distribution of health care resources, particularly when the disability status of patients is considered alongside life-expectancy or quality of life. ${ }^{3}$

Crisis standards of care (CSC) prioritize population-level health under a utilitarian paradigm, explicitly maximizing "life-years" within a population of patients rather than the life of any individual patient. ${ }^{4}$ Debated during initial COVID surges, these CSC guidelines have recently been enacted at the state level in several settings, including Alaska and Idaho. ${ }^{5}$ In a setting with scarce intensive care resources, balancing health equity in access to these resources against population-based survival metrics has been a challenge for commissions considering CSC. ${ }^{6,7}$ This need for balance has further promoted systemic views of "disability," raising concern for structural "ableism" and highlighting the need for greater "ability awareness" in clinicians' continued professional learning.

\section{Structural Ableism: Defining Perspectives to Address Health Equity}

Ableism has been defined as "a system that places value on people's bodies and minds, based on societally constructed ideas of normalcy, intelligence, excellence, and productivity... [and] leads to people and society determining who is valuable and worthy based on their appearance and/or their ability to satisfactorily [re]produce, excel, and "behave."'8 Regarding CSC, concerns about systemic bias in guideline design were raised early by disability advocacy groups during comment periods. ${ }^{9,10}$ More broadly, concerns about ableism sit alongside many deeply rooted societal perspectives of disabled individuals as pitiable or, conversely, heroic for having "overcome" their disability in some way. As a physician who sits in a manual wheelchair with paraplegia and mobility impairment, I have equally been subject to inappropriate bias and inappropriate praise for living in a wheelchair. I have also wondered, alongside my patients living with different levels of mobility or ability, why others often view us as "worse off." Addressing directly whether disabled individuals are "worse off," disability rights attorney and advocate Harriet McBryde Johnson has articulated a predominant sentiment among persons living with unique or different abilities:

Are we "worse off"? I don't think so. Not in any meaningful way. There are too many variables. For those of us with congenital conditions, disability shapes all we are. Those disabled later in life adapt.

From Tufts University School of Medicine, Boston, MA. 
We take constraints that no one would choose and build rich and satisfying lives within them. We enjoy pleasures other people enjoy and pleasures peculiarly our own. We have something the world needs. ${ }^{11}$

Many physician colleagues have common, invisible diseases such as diabetes and heart disease; fewer colleagues share conditions that are as visible as my spinal cord injury, as readily apparent to patients upon my entry to their hospital rooms. This simultaneous and inescapable identity as both patient and provider has afforded me wonderful doctor-patient interactions, particularly with those patients who appreciate how my patient experience impacts my ability to partially understand theirs. However, this simultaneous identity as doctor and patient also informed my personal and professional concerns regarding structural ableism as I considered scoring my own acutely ill hospital medicine patients with CSC triage scores in April 2020.

As a practicing hospital medicine physician, I have been emboldened by the efforts of my fellow clinicians amid COVID-19; their efforts have reaffirmed all the reasons I pursued a career in medicine. However, when I heard my clinical colleagues' first explanation of the Massachusetts CSC guidelines in April 2020, I raised my hand to ask whether the "life-years" to which the guidelines referred were quality-adjusted. My concern regarding the implicit use of quality-adjusted life years (QALY) or disability-adjusted life years in clinical decision-making and implementation of these guidelines was validated when no clinical leaders could address this question directly. Sitting on the CSC committee for my hospital during this time was an honor. However, it was disconcerting to hear many clinicians' unease when estimating mean survival for common chronic diseases, ranging from end-stage renal disease to advanced heart failure. If my expert colleagues, clinical specialists in kidney and heart disease, could not confidently apply mean survival estimates to multimorbid hospital patients, then idiosyncratic clinical judgment was sure to have a heavy hand in any calculation of "life-years." Thus, my primary concern was that clinicians using triage heuristics would be subject to bias, regardless of their intention, and negatively adjust for the quality of a disabled life in their CSC triage scoring. My secondary concern was that the CSC guidelines themselves included systemic bias against disabled individuals.

According to CSC schema, triage scores index heavily on Sequential Organ Failure Assessment (SOFA) scores to define short-term survival; SOFA scores are partially driven by the Glasgow Coma Scale (GCS). Following professional and public comment periods, CSC guidelines in Massachusetts were revised to, among other critical points of revision, change prognostic estimation via "life years" in favor of generic estimation of short-term survival (Table). I wondered, if I presented to an emergency department with severe COVID-19 and was scored with the GCS for the purpose of making a CSC ventilator triage decision, how would my complete paraplegia and lower-extremity motor impairment be accounted for by a clinician assessing "best motor response" in the GCS? The purpose of these scores is to act algorithmically, to guide clinicians whose cognitive load and time limitations may not allow for adjustment of these algorithms based on the individual patient in front of them. Individualization of clinical decisions is part of medicine's art, but is difficult in the best of times and no easier during a crisis in care delivery. As CSC triage scores were amended and addended throughout 2020, I returned to the COVID wards, time and again wondering, "What have we learned about systemic bias and health inequity in the CSC process and the pandemic broadly, with specific regard to disability?"

\section{Ability Awareness: Room \\ for Our Improvement}

Unfortunately, there is reason to believe that clinical judgment is impaired by structural ableism. In seminal work on this topic, Gerhart et al ${ }^{12}$ demonstrated that clinicians considered spinal cord injury (SCl) survivors to have low self-perceptions of worthiness, overall negative attitudes, and low self-esteem as compared to able-bodied individuals. However, surveyed SCl survivors generally had similar self-perceptions of worth and positivity as compared to "able-bodied" clinicians. ${ }^{12}$ For providers who care for persons with disabilities, the majority (82.4\%) have rated their disabled patients' quality of life as worse..$^{13}$ It is no wonder that patients with disabilities are more likely to feel that their doctor-patient relationship is impacted by lack 
Table. Massachusetts Crisis Standards of Care Triage Point System (April 7, 2020) and Revision of Specifications (April 20, 2020)

\begin{tabular}{|c|c|c|c|c|c|}
\hline \multicolumn{6}{|c|}{ Multi-principle Strategy to Allocate Critical Care to Adult Patients During a Public Health Emergency (April 7, 2020) } \\
\hline \multirow[b]{2}{*}{ Principle } & \multirow[b]{2}{*}{ Specification } & \multicolumn{4}{|c|}{ Point System* } \\
\hline & & 1 & 2 & 3 & 4 \\
\hline Save the most lives & $\begin{array}{l}\text { Prognosis for } \\
\text { short-term survival } \\
\text { (SOFA score) }\end{array}$ & SOFA score $<6$ & SOFA score 6-9 & SOFA score 10-12 & SOFA score $>12$ \\
\hline $\begin{array}{l}\text { Save the most life- } \\
\text { years }\end{array}$ & $\begin{array}{l}\text { Prognosis } \\
\text { for long-term } \\
\text { survival (medical } \\
\text { assessment } \\
\text { of comorbid } \\
\text { conditions) }\end{array}$ & - & $\begin{array}{l}\text { Major comorbid } \\
\text { conditions with } \\
\text { substantial impact } \\
\text { on long-term } \\
\text { survival }\end{array}$ & - & $\begin{array}{l}\text { Severe comorbid } \\
\text { conditions; death } \\
\text { likely within } 1 \text { year }\end{array}$ \\
\hline \multicolumn{6}{|c|}{ Multi-principle Strategy to Allocate Critical Care to Adult Patients During a Public Health Emergency (April 20, 2020) } \\
\hline & & \multicolumn{4}{|c|}{ Point System ${ }^{\star}$} \\
\hline & Specification & 1 & 2 & 3 & 4 \\
\hline & $\begin{array}{c}\text { Prognosis for } \\
\text { survival of the acute } \\
\text { illness }\end{array}$ & SOFA score $<6$ & SOFA score 6-9 & SOFA score 10-12 & SOFA score >12 \\
\hline & $\begin{array}{l}\text { Prognosis for } \\
\text { survival beyond the } \\
\text { acute illness }\end{array}$ & - & - & - & $\begin{array}{l}\text { Severely life-limiting } \\
\text { conditions; death } \\
\text { likely within } 1 \\
\text { year regardless of } \\
\text { whether patient } \\
\text { survives the acute } \\
\text { illness }\end{array}$ \\
\hline
\end{tabular}

SOFA, Sequential Organ Failure Assessment.

*Persons with the lowest cumulative score will be given the highest priority to receive critical care services.

of understanding, negative sentiment, or simple lack of listening..$^{14}$ Generally, this poor doctor-patient relationship with disabled patients is exacerbated by poor exposure of medical trainees to disability education; only $34.2 \%$ of internal medicine residents recall any form of disability education in medical school, while only $52 \%$ of medical school deans report having disability educational content in their curricula. ${ }^{15,16}$ There is a similar lack of disability representation in the population of medical trainees themselves. While approximately $20 \%$ of the American population lives with a disability, less than $2 \%$ of American medical students have a disability. ${ }^{17-19}$

While representation of disabled populations in medical practice remains poor, disabled patients are generally less likely to receive age-appropriate prevention, appropriate access to care, and equal access to treatment. ${ }^{20-22}$
"Diagnostic overshadowing" refers to clinicians' attribution of nonspecific signs or symptoms to a patient's chronic disability as opposed to acute illness. ${ }^{23}$ This phenomenon has led to higher rates of preventable malignancy in disabled patients and misattribution of common somatic symptoms to intellectual disability. ${ }^{24,25}$ With this disparity in place as status quo for health care delivery to disabled populations, it is no surprise that certain portions of the disabled population have accounted for disproportionate mortality due to COVID-19.26,27

Disability advocates have called for "nothing about us without us," a phrase associated with the United Nations Convention on the Rights of Persons with Disabilities. Understanding the profound neurodiversity among several forms of sensory and cognitive disabilities, as well as the functional difference between cognitive disabilities, mobility 
impairment, and inability to meet one's instrumental activities of daily living independently, others have proposed a unique approach to certain disabled populations in COVID care. ${ }^{28} \mathrm{My}$ own perspective is that definite progress may require a more general understanding of the prevalence of disability by clinicians, both via medical training and by directly addressing health equity for disabled populations in such calculations as the CSC. Systemic ableism is apparent in our most common clinical scoring systems, ranging from the GCS and Functional Assessment Staging Table to the Eastern Cooperative Oncology Group and Karnofsky Performance Status scales. I have reexamined these scoring systems in my own understanding given their general equation of ambulation with ability or normalcy. As a doctor in a manual wheelchair who values greatly my personal quality of life and professional contribution to patient care, I worry that these scoring systems inherently discount my own equitable access to care. Individualization of patients' particular abilities in the context of these scales must occur alongside evidence-based, guideline-directed management via these scoring systems.

\section{Conclusion: Future Orientation}

Updated CSC guidelines have accounted for the unique considerations of disabled patients by effectively caveating their scoring algorithms, directing clinicians via disclaimers to uniquely consider their disabled patients in clinical judgement. This is a first step, but it is also one that erodes the value of algorithms, which generally obviate more deliberative thinking and individualization. For our patients who lack certain abilities, as CSC continue to be activated in several states, we have an opportunity to pursue more inherently equitable solutions before further suffering accrues. ${ }^{29}$ By way of example, adaptations to scoring systems that leverage QALYs for value-based drug pricing indices have been proposed by organizations like the Institute for Clinical and Economic Review, which proposed the Equal-Value-of Life-Years-Gained framework to inform QALY-based arbitration of drug pricing. ${ }^{30}$ This is not a perfect rubric but instead represents an attempt to balance consideration of drugs, as has been done with ventilators during the pandemic, as a scare and expensive resource while addressing the just concerns of advocacy groups in structural ableism.
Resource stewardship during a crisis should not discount those states of human life that are perceived to be less desirable, particularly if they are not experienced as less desirable but are experienced uniquely. Instead, we should consider equitably measuring our intervention to match a patient's needs, as we would dose-adjust a medication for renal function or consider minimally invasive procedures for multimorbid patients. COVID-19 has reflected our profession's ethical adaptation during crisis as resources have become scarce; there is no better time to define solutions for health equity. We should now be concerned equally by the influence our personal biases have on our clinical practice and by the way in which these crisis standards will influence patients' perception of and trust in their care providers during periods of perceived plentiful resources in the future. Health care resources are always limited, allocated according to societal values; if we value health equity for people of all abilities, then we will consider these abilities equitably as we pursue new standards for health care delivery.

Corresponding author: Gregory D. Snyder, MD, MBA, 2014 Washington Street, Newton, MA 02462; gdsnyder@bwh.harvard.edu.

Disclosures: None.

Keywords: disability, crisis standards of care, clinical decisionmaking, resource stewardship.

doi: 10.12788/jcom.0081

\section{References}

1. Emanuel EJ, Persad G, Upshur R, et al. Fair Allocation of scarce medical resources in the time of Covid-19. $N$ Engl $J$ Med. 2020;382(21):2049-2055. doi:10.1056/NEJMsb2005114

2. Savulescu J, Persson I, Wilkinson D. Utilitarianism and the pandemic. Bioethics. 2020;34(6):620-632. doi:10.1111/bioe.12771

3. Mello MM, Persad G, White DB. Respecting disability rights - toward improved crisis standards of care. N Engl J Med. 2020;383(5):e26. doi: 10.1056/NEJMp2011997

4. The Commonwealth of Massachusetts Executive Office of Health and Human Services Department of Public Health. Crisis Standards of Care Planning Guidance for the COVID-19 Pandemic. April 7, 2020. https://d279m997dpfwgl.cloudfront.net/wp/2020/04/CSC_ April-7_2020.pdf

5. Knowles H. Hospitals overwhelmed by covid are turning to "crisis standards of care.' What does that mean? The Washington Post. September 21, 2021. Accessed January 24, 2022. https://www. washingtonpost.com/health/2021/09/22/crisis-standards-of-care/

6. Hick JL, Hanfling D, Wynia MK, Toner E. Crisis standards of care and COVID-19: What did we learn? How do we ensure equity? What should we do? NAM Perspect. 2021;2021:10.31478/202108e. doi:10.31478/202108e 
7. Cleveland Manchanda EC, Sanky C, Appel JM. Crisis standards of care in the USA: a systematic review and implications for equity amidst COVID-19. J Racial Ethn Health Disparities. 2021;8(4):824836. doi:10.1007/s40615-020-00840-5

8. Cleveland Manchanda EC, Sanky C, Appel JM. Crisis standards of care in the USA: a systematic review and implications for equity amidst COVID-19. J Racial Ethn Health Disparities. 2021;8(4):824836. doi:10.1007/s40615-020-00840-5

9. Kukla E. My life is more 'disposable' during this pandemic. The New York Times. March 19, 2020. Accessed January 24, 2022. https://www.nytimes.com/2020/03/19/opinion/coronavirus-disabled-health-care.html

10. CPR and Coalition Partners Secure Important Changes in Massachusetts' Crisis Standards of Care. Center for Public Representation. December 1, 2020. Accessed January 24, 2022. https://www.centerforpublicrep.org/news/cpr-and-coalition-partners-secure-important-changes-in-massachusetts-crisis-standards-of-care/

11. Johnson HM. Unspeakable conversations. The New York Times. February 16, 2003. Accessed January 24, 2022. https://www. nytimes.com/2003/02/16/magazine/unspeakable-conversations.html.

12. Gerhart KA, Koziol-McLain J, Lowenstein SR, Whiteneck GG. Quality of life following spinal cord injury: knowledge and attitudes of emergency care providers. Ann Emerg Med. 1994;23(4):807-812. doi:10.1016/s0196-0644(94)70318-3

13. lezzoni LI, Rao SR, Ressalam J, et al. Physicians' perceptions of people with disability and their health care. Health Aff (Millwood). 2021;40(2):297-306. doi:10.1377/hlthaff.2020.01452

14. Smith DL. Disparities in patient-physician communication for persons with a disability from the 2006 Medical Expenditure Panel Survey (MEPS). Disabil Health J. 2009;2(4):206-215. doi:10.1016/ j.dhjo.2009.06.002

15. Stillman MD, Ankam N, Mallow M, Capron M, Williams S. A survey of internal and family medicine residents: Assessment of disability-specific education and knowledge. Disabil Health J. 2021;14(2):101011. doi:10.1016/j.dhjo.2020.101011

16. Seidel E, Crowe S. The state of disability awareness in American medical schools. Am J Phys Med Rehabil. 2017;96(9):673-676. doi:10.1097/PHM.0000000000000719

17. Okoro CA, Hollis ND, Cyrus AC, Griffin-Blake S. Prevalence of disabilities and health care access by disability status and type among adults - United States, 2016. MMWR Morb Mortal Wkly Rep. 2018;67(32):882-887. doi:10.15585/mmwr.mm6732a3

18. Peacock G, lezzoni LI, Harkin TR. Health care for Americans with disabilities--25 years after the ADA. N Engl J Med. 2015;373(10):892893. doi:10.1056/NEJMp1508854

19. DeLisa JA, Thomas P. Physicians with disabilities and the physician workforce: a need to reassess our policies. Am $J$ Phys Med Rehabil. 2005;84(1):5-11. doi:10.1097/01 .phm.0000153323.28396.de

20. Disability and Health. Healthy People 2020. Accessed January 24, 2022. https://www.healthypeople.gov/2020/topics-objectives/ topic/disability-and-health

21. Lagu T, Hannon NS, Rothberg MB, et al. Access to subspecialty care for patients with mobility impairment: a survey. Ann Intern Med. 2013;158(6):441-446. doi: 10.7326/0003-4819-158-6-201303190-00003

22. McCarthy EP, Ngo LH, Roetzheim RG, et al. Disparities in breast cancer treatment and survival for women with disabilities. Ann Intern Med. 2006;145(9):637-645. doi: 10.7326/0003-4819-145-9-200611070-00005

23. Javaid A, Nakata $\bigvee$, Michael D. Diagnostic overshadowing in learning disability: think beyond the disability. Prog Neurol Psychiatry. 2019;23:8-10

24. lezzoni LI, Rao SR, Agaronnik ND, El-Jawahri A. Cross-sectional analysis of the associations between four common cancers and disability. J Natl Compr Canc Netw. 2020;18(8):1031-1044. doi:10.6004/jnccn.2020.7551

25. Sanders JS, Keller S, Aravamuthan BR. Caring for individuals with intellectual and developmental disabilities in the COVID-19 crisis. Neurol Clin Pract. 2021;11(2):e174-e178. doi:10.1212/ CPJ.0000000000000886

26. Landes SD, Turk MA, Formica MK, McDonald KE, Stevens JD. COVID-19 outcomes among people with intellectual and developmental disability living in residential group homes in New York State. Disabil Health J. 2020;13(4):100969. doi:10.1016/ j.dhjo.2020.100969

27. Gleason J, Ross W, Fossi A, Blonksy H, Tobias J, Stephens M. The devastating impact of Covid-19 on individuals with intellectual disabilities in the United States. NEJM Catalyst. 2021.doi.org/10.1056/ CAT.21.0051

28. Nankervis K, Chan J. Applying the CRPD to people with intellectual and developmental disability with behaviors of concern during COVID-19. J Policy Pract Intellect Disabil. 2021:10.1111/ jppi.12374. doi:10.1111/jppi.12374

29. Alaska Department of Health and Social Services, Division of Public Health, Rural and Community Health Systems. Patient care strategies for scarce resource situations. Version 1. August 2021. Accessed November 11, 2021, https://dhss.alaska. gov/dph/Epi/id/SiteAssets/Pages/HumanCoV/SOA_DHSS_ CrisisStandardsOfCare.pdf

30. Cost-effectiveness, the QALY, and the evlyg. ICER. May 21, 2021. Accessed January 24, 2022. https://icer.org/our-approach/ methods-process/cost-effectiveness-the-qaly-and-the-evlyg/ 